\title{
DESENVOLVIMENTO SUSTENTÁVEL X DESENVOLVIMENTO ECONÔMICO
}

\author{
SUSTAINABLE ECONOMIC DEVELOPMENT DEVELOPMENT X
}

\author{
Nathália Leal de Carvalho; Cristiano Kersting2; Gilvan Rosa²; Lumar Fruet²; Afonso Lopes de \\ Barcellos ${ }^{3}$.
}

${ }^{1}$ Doutoranda do Programa de Pós Graduação em Agronomia/UPF - nathaliiinha@hotmail.com; ${ }^{2}$ Curso Superior de Tecnologia dó Agronegócio/IFF - Campus Júlio de Castilhos - criskersting@gmail.com; ${ }^{3}$ Mestrando em Desenvolvimento Rural/UNICRUZ - lopesdelopes@hotmail.com.

\begin{abstract}
Resumo
Desenvolvimento sustentável é o uso racional dos recursos naturais em prol do bem-estar social, garantindo o crescimento econômico necessário para suprir as nossas demandas e as necessidades das futuras gerações. Com o objetivo de identificar às origens conceituais e algumas práticas direcionadas a sustentabilidade desenvolveu-se o estudo. Os recursos naturais têm se tornado cada vez mais escassos, devendo-se levar em consideração sua possivel exaustão. Com essa ameaça, buscam-se alternativas para que o desenvolvimento sócioeconômico seja sustentável. Uma política social forte é ainda a principal necessidade para a conquista do desenvolvimento sustentável, principalmente nos países emergentes assim como o Brasil. Questões ambientais, relacionadas ao uso de agrotóxicos, desmatamento excessivo, mão de obra escrava e infantil são alguns dos fatores que as políticas públicas tentam inibir, porém continuam agindo de forma lenta e ineficaz na maioria dos estados brasileiros. Assim há uma emergente mudança de paradigmas sociais, onde é necessário perceber valores que direcionam nosso desenvolvimento econômico e nossa relação com o meio ambiente. O uso da sustentabilidade torna-se o grande desafio social das próximas décadas.
\end{abstract}

Palavras-chave: Políticas, Sustentabilidade, Equilíbrio Ambiental.

\begin{abstract}
Sustainable development is the rational use of natural resources for the welfare, ensuring the economic growth needed to meet our demands and the needs of future generations. In order to identify the conceptual origins and some practices aimed at sustainability developed the study. Natural resources are becoming increasingly scarce, and that they take into account their possible exhaustion. With this threat, alternatives are sought for the socio-economic development is sustainable. A strong social policy is still the main need for the achievement of sustainable development, especially in emerging countries like Brazil. Environmental issues related to the use of pesticides, excessive deforestation, hand slave and child labor are some of the factors that public policies attempt to inhibit, but continues to act slowly and ineffectively in most states. So there is an emerging change of social paradigms, where it is necessary to realize values that drive our economic development and our relationship with the environment. The use of sustainability becomes the great social challenge of the coming decades.
\end{abstract}

Keywords: learning Policy, Sustainability, Environmental Balance. 


\section{Introdução}

O conceito de desenvolvimento sustentável (DS) surgiu a nível mundial no relatório de Brundtland em 1987, fruto de análises coordenadas pela Comissão Mundial sobre o meio Ambiente e o desenvolvimento criada em 1983 pela Assembléia Geral das nações unidas, com o propósito de desenvolver o crescimento econômico e superar a pobreza dos países desenvolvidos e em desenvolvimento.

"Este em muito contribuiu para impor a referência ao desenvolvimento sustentável como novo elemento semântico da linguagem internacional e como elemento de focalização dos trabalhos dos peritos das organizações internacionais (Hatem apud Godard, 1997a, p.110).

No Brasil, em 1992 a conferência das nações unidas sobre o meio ambiente e desenvolvimento (Rio 92, ECO 92 ou CUPULA DA TERRA) mostrou para a humanidade a responsabilidade e a necessidade da conciliação entre o desenvolvimento econômico, social e a utilização dos recursos naturais. Os participantes do evento chegaram a um consenso de que os países desenvolvidos eram os maiores responsáveis pelos danos ao meio ambiente e que os países em desenvolvimento necessitavam de apoio financeiro e tecnológico para caminhar ao novo conceito de sustentabilidade. $\mathrm{O}$ fato mais importante é que a partir deste evento ficou concretizado o conceito de DS.

Temos de fazer um paralelo entre crescimento e desenvolvimento. A diferença é que o crescimento não conduz automaticamente à igualdade nem à justiça sociais, pois não leva em consideração nenhum outro aspecto da qualidade de vida a não ser o acúmulo de riquezas, que se faz nas mãos apenas de alguns indivíduos da população. $O$ desenvolvimento, por sua vez, preocupa-se com a geração de riquezas sim, mas tem o objetivo de distribuí-las, de melhorar a qualidade de vida de toda a população, levando em consideração, portanto, a qualidade ambiental do planeta (MENDES, 2008).

Acreditamos que isso tudo seja possível, e é exatamente o que propõem os estudiosos em DS, que pode ser definido como: equilíbrio entre tecnologia e ambiente, relevando-se os diversos grupos sociais de uma nação e também dos diferentes países na busca da equidade e justiça social.

O DS é composto pelas dimensões econômica, ambiental e empresarial. O objetivo é obter crescimento econômico por meio da preservação do meio ambiente e pelo respeito aos anseios dos diversos agentes sociais, contribuindo assim para a melhoria da qualidade de vida da sociedade (TENÓRIO, 2004), neste propósito iremos discorrer sobre o conceito do desenvolvimento sustentável, enfatizando as relações políticas, econômicas e sociais.

\section{SUSTENTABILIDADE COMO UM DESAFIO}

Após a década de 60, início dos anos 70, surgiram diversas correntes de pensamentos acerca do futuro, das mudanças climáticas e as relações sociais perante o meio ambiente. A conferência das nações unidas firmou um conceito mundial de "desenvolvimento sustentável", que expressa sentimentos coletivos de liberdade e democracia, com isso o mundo passou a questionar e repensar um futuro em prol do bem comum. 
Para José Eli da Veiga (2005), esses sentimentos coletivos "Nosso Futuro comum" e o próprio conceito de desenvolvimento sustentável estão ainda em construção, pois não podemos definir nem mensurar as necessidades do presente, muito menos quais serão as necessidades do futuro.

A equidade social e ambiental fica atrelada ao desenvolvimento econômico, desta forma, para criar alternativas sustentáveis, é preciso conhecer o comportamento humano, seus hábitos de consumo e modos de produção, sendo para Veiga, um enigma a ser descoberto.

No livro "Desenvolvimento Sustentável: o desafio para o século XXI" ele afirma que o conceito de desenvolvimento sustentável é uma utopia para o século XXI, apesar de defender a necessidade de se buscar um novo paradigma científico capaz de substituir os paradigmas do "globalismo" (VEIGA, 2005).

Com a criação de um conceito global acerca da sustentabilidade, os países desenvolvidos principais causadores de danos ao meio ambiente e defensores do capitalismo, pressionados por ONGs em defesa ao meio ambiente, passaram a desenvolver acordos como ECO 92 (Rio de Janeiro 1992), Protocolo de Kyoto (Japão 1997) dentre outros, com o objetivo de controlar as expectativas globais.

O que se percebe, que embora, assumindo maiores compromissos, os países ricos e industrializados, oferecem resistência no cumprimento dos acordos. Em prova disso, no ano de 2005 apenas os países ricos não tinham atingidos as metas previstas pelos acordos (PRAHALAD, 2005).

Para alcançarmos o DS, a proteção do ambiente tem que ser entendida como parte integrante do processo de desenvolvimento e não pode ser considerada isoladamente (MENDES, 2008).

DS tem seis aspectos prioritários que devem ser entendidos como metas: A satisfação das necessidades básicas da população (educação, alimentação, saúde, lazer, etc.); A solidariedade para com as gerações futuras (preservar o ambiente de modo que elas tenham chance de viver); A participação da população envolvida (todos devem se conscientizar da necessidade de conservar o ambiente e cada um a parte que lhe cabe para tal); A preservação dos recursos naturais (água, oxigênio, etc.); A elaboração de um sistema social garantindo emprego, segurança social e respeito a outras culturas (erradicação da miséria, do preconceito e do massacre de populações oprimidas, como por exemplo, os índios); A efetivação dos programas educativos (MENDES, 2008).

Para ser alcançado, o DS depende de planejamento e do reconhecimento de que os recursos naturais são finitos. Esse conceito representou uma nova forma de desenvolvimento econômico e a adoção e o aumento da reutilização e da reciclagem. Na tentativa de se chegar ao DS, sabe-se que a Educação Ambiental é parte vital e indispensável, pois é a maneira mais direta e funcional de se atingir suas metas.

Para elucidar de forma gráfica a dinâmica de funcionamento de um sistema de desenvolvimento econômico de transformação social, temos na Figura 01 um ciclo no qual devem atuar em parcerias as redes locais. 


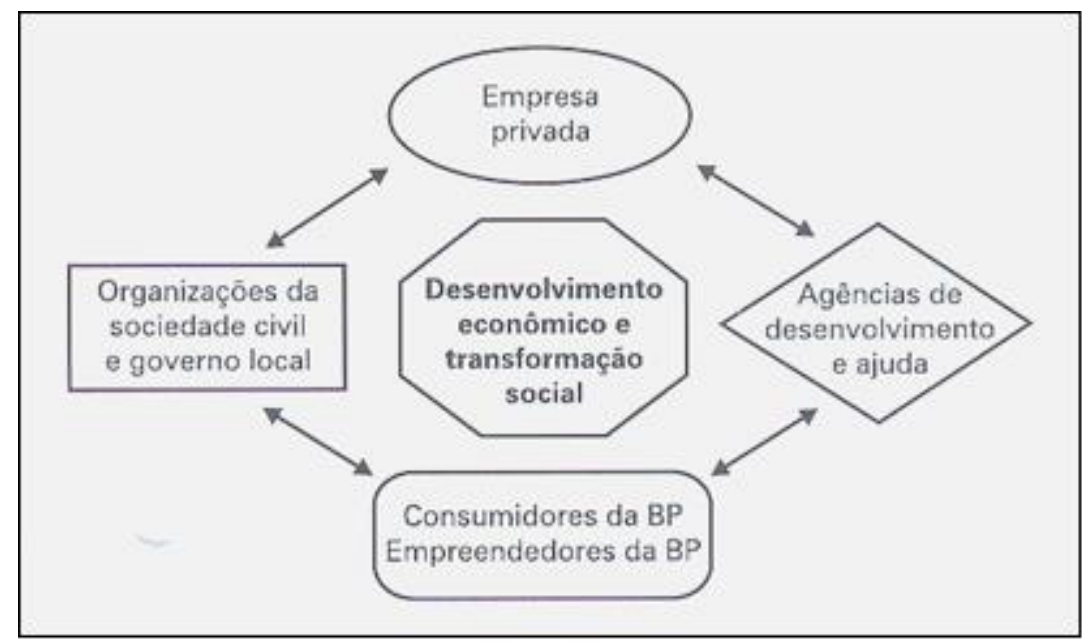

Figura 1- Rede de desenvolvimento sócio-econômico. Fonte: PRAHALAD, 2005.

Mas modelo de desenvolvimento econômico baseado no capitalismo e que tem como característica a transformação das relações em mercadoria e como objetivo o lucro, é incompatível com o desenvolvimento sustentável uma vez que este alcança uma dimensão holística na relação entre os seres humanos e entre a humanidade e a natureza não contemplada pelo capitalismo. O DS busca suprir as demandas do presente, sem comprometer a capacidade das gerações futuras de responder às suas necessidades. É aquele que procura no presente preencher as lacunas econômicas, sociais, ambientais, políticas (no que tange a transparência e participação), além dos direitos humanos inclusive o direito a um meio ambiente limpo e seguro - buscando-se conjuntamente a conservação destes para as gerações futuras

Ao unirmos as palavras "Desenvolvimento" e "Sustentável" podemos perceber a emergência de um conceito contraditório. Desenvolvimento é entendido muitas vezes como crescimento, o que implica num incremento físico ou material da produção, enquanto que sustentável diz respeito a alguma atividade que possui continuidade a longo prazo (TENÓRIO, 2006).

A ideia de crescimento constante e infinito justamente pode ser comparada a uma célula cancerígena no ser humano, que, se não tratada em tempo hábil, pode tornar-se fatal. Este crescimento infinito nos faz refletir sobre os limites ecológicos que não podemos ultrapassar, pois, caso contrário, adentraremos num processo irreversível de degradação e escassez.

O crescimento é crucial se quisermos satisfazer as necessidades humanas, porém existem limites e obstáculos que devem ser mensurados, pois o " $\mathrm{x}$ " da questão está em determinar que tipo de crescimento é necessário para atender as necessidades humanas (MENDES, 2008).

\subsection{Políticas}

O constante crescimento da população mundial gera preocupações, pois o esgotamento da água, a emissão de gases, o consumo exagerado, fruto do sistema capitalista, são fatores incontroláveis pelas políticas atuais.

A dificuldade atual dos governos não é a criação de leis, mas sim o processo todo de execução e acompanhamento que na maioria dos casos fica a desejar. 
Segundo Pedro Campany (2010), o código florestal brasileiro constituído pela lei 4775/65 que estipulou como áreas de preservação permanente uma serie de espaços territoriais como topos de morros, áreas com declividade, áreas marginais como rios e lagos, afirma que a indefinição de limites gerou diversos problemas como a falta de fiscalização e aplicação da lei.

O código deixou lacunas no que tange a metragens dá área de preservação, sendo então suplantado pelo poder executivo por meio de resoluções do conselho nacional do meio ambiente (CONAMA), contudo o judiciário e o executivo, não conseguem, criar normas e muito menos resolver os conflitos decorrentes dos limites ou a ausência das metragens.

A inércia das políticas é o principal entrave para os governos atuais no cumprimento das leis e execução dos planejamentos de desenvolvimento sustentável.

Existem ações nacionais e internacionais, que foram bem sucedidas, dentre elas, podemos citar, algumas punições no ano de 2008, contra crimes de desmatamento, biopirataria, e exploração indiscriminada de recursos da fauna.

As cidades crescem indiscriminadamente sem qualquer planejamento urbano, favorecendo a formação de favelas, ocupação descontrolada das áreas de preservação, que ocasionam em grandes catástrofes, como os desmoronamentos de morros, alagamentos, enchentes e poluição de rios e nascentes (FERREIRA, 1988).

A falta de aplicação e acompanhamento das políticas ambientais e habitacionais proporciona para nossas grandes cidades uma perda de qualidade de vida e um desequilíbrio social e sustentável.

"o padrão de produção e consumo que caracteriza o atual estilo de desenvolvimento tende a consolidar-se no espaço das cidades e estas se tornam cada vez mais o foco principal na definição de estratégias e políticas de desenvolvimento" (FERREIRA, 1998).

Para que uma sociedade seja sustentável, é necessário haver a integração do desenvolvimento com a conservação ambiental. A política econômica pode ser um eficaz instrumento para a sustentação dos ecossistemas e dos recursos naturais. Na falta de incentivos econômicos adequados, as políticas e as legislações que visam a proteção do meio ambiente e a conservação de recursos serão desconsideradas. Os sistemas convencionais costumam lidar com o meio ambiente e suas funções como sendo ilimitados ou gratuitos, desta forma, incentivam a exaustão dos recursos e a degradação dos ecossistemas. Todas as economias dependem do meio ambiente como fonte de serviços de sustentação da vida e de matérias-primas, portanto, os mercados e as economias planejadas deverão se conscientizar do valor desses bens e serviços, ou dos custos que a sociedade terá, caso os recursos ambientais sejam reduzidos ou os serviços, prejudicados.

Até a Conferência das Nações Unidas para o Meio Ambiente e o Desenvolvimento (CNUMAD) a ECO-92, o pensamento brasileiro considerava o lixo um problema municipal, de responsabilidade das prefeituras. Hoje, a questão do lixo no Brasil é pauta urgente para o poder público, empresas privadas e para a própria sociedade civil organizada. No bojo dos números do IBGE, se escondem algumas iniciativas que pretendem transformar a natureza humana através da filosofia dos três "Rs": Reduzir/Reciclar/Reutilizar.

A redução é uma forma de reduzir o consumo exagerado e quando for consumir, fazer de maneira mais eficiente.

A reciclagem é um termo utilizado para quando o material pode ser refeito por indústrias especializadas, tornando um produto novo que já foi utilizado e descartado, bom para uso. A reciclagem promove economia de recursos naturais, diminuição nos gastos com 
limpeza pública, nos tratamentos das doenças, no controle da poluição e na construção de aterros, além de diminuir o acúmulo de dejetos. Poupa também a natureza da extração inesgotável de seus recursos.

A reutilização é uma forma de evitar o desperdício, que é o meio irracional de se utilizar recursos e produtos, que podem ser reutilizados antes de serem jogados fora.

Segundo o Instituto Ethos no artigo Mostra de Tecnologias Sustentáveis 2009, há que se pensar em tecnologias economicamente corretas e que não depredem o meio ambiente, as chamadas tecnologias sustentáveis que compreendem metodologias, técnicas, sistemas, equipamentos ou processos economicamente viáveis e passíveis de serem reproduzidos e aplicados, de forma a minimizar os impactos negativos e a promover impactos positivos no meio ambiente, na qualidade de vida das pessoas e na sustentabilidade da sociedade.

Por sua vez os governos têm grande responsabilidade no que diz respeito ao destino do lixo, a ele compete: Conscientizar a população sobre o lixo e estimular mudanças de atitude; fazer e usar os instrumentos que incentivem a redução; usar seu poder de compra e adquirir matérias primas recicladas ou componentes reciclados; valorizar e apoiar os catadores e cooperativas de coleta de lixo e reciclagem; responsabilizar os produtores que não coletam devidamente o lixo que produzem; realizar serviços eficientes de limpeza pública (SEBILIA, 2007).

Para isso, faz-se necessário promover a consciência ambiental através do desenvolvimento sustentável, consumindo com menos desperdício, reutilizando e reciclando seus recursos. A conscientização e a prevenção são essenciais para garantir o desenvolvimento sustentável e diminuir o impacto causado ao meio ambiente e a todas as formas de vida.

Mas o grande desafio é que o ser humano só vai dar o tratamento adequado ao lixo que produz, quando reciclar seu modo de viver, produzir e consumir!

\section{EQUILÍBRIO AMBIENTAL}

"Tudo o que acontece a terra, acontece aos filhos da terra. O homem não teceu a teia da vida, é meramente um fio dela. O que quer que faça a teia, ela faz a si mesmo" (IACOMINNI, 2011).

Atualmente, a racionalidade humana prioriza a busca pelo lucro nas atividades em que atua, deixando de lado questões éticas primordiais na conservação de tudo o que representa vida para a espécie humana.

Conforme (CANEPA, 2007) o desenvolvimento sustentável depende diretamente do equilíbrio entre o comportamento social, nossa relação com o meio ambiente e o processo de mudanças na exploração dos recursos naturais, também esta relacionado com o bom gerenciamento dos investimentos tecnológicos, promovido pelas instituições públicas e privadas.

No ano de 1977 a conferencia intergovernamental sobre Educação Ambiental realizada na cidade de Tsibilisi (EUA), propôs a criação de novos modelos de produção do conhecimento, com a finalidade de formar uma nova consciência global sobre a importância da natureza.

A educação ambiental, deve ser abordada como mecanismo para explicar a relação do homem com a natureza e praticar hábitos de cidadania (Carvalho, 2001). 
É preciso reavaliar eticamente comportamentos, primar por condutas responsáveis e inteligentemente, posicionarmo-nos neste planeta como únicos seres viventes com obrigações ambientais.

Para algumas ONGS, a natureza tem sido a alma do negócio, afinal, com criatividade e atitude, muitas atividades de exploração agropecuária e extrativista podem ser inovadas.

Projetos estudados já foram bem sucedidos e apresentaram resultados desejáveis economicamente e de acordo com os preceitos da sustentabilidade. A exemplo do projeto Cana Verde criado em 1986, cujo objetivo era a geração de uma energia limpa, econômica e renovável, este, foi atingido no ano de 1997, conhecido como energia da biomassa, caracterizada por uma estratégia sustentável, sem riscos para o meio ambiente utilizando controle biológico de pragas.

Promover equilíbrio ambiental representa uma mudança ética e moral de cada cidadão, uma reeducação nos hábitos de consumo. A atitude de cada consumidor é que vai determinar os novos rumos da exploração dos recursos naturais.

Exemplos como a criação do selo verde, a rastreabilidade animal, dentre outros, para os quais foram criados controles de qualidade necessários para atender as demandas do consumidor informado e exigente (TENÓRIO, 2006).

Para alcançarmos o DS, a proteção do ambiente tem que ser entendida como parte integrante do processo de desenvolvimento e não pode ser considerada isoladamente; é aqui que entra uma questão sobre a qual talvez você nunca tenha pensado: qual a diferença entre crescimento e desenvolvimento? A diferença é que o crescimento não conduz automaticamente à igualdade nem à justiça sociais, pois não leva em consideração nenhum outro aspecto da qualidade de vida a não ser o acúmulo de riquezas, que se faz nas mãos apenas de alguns indivíduos da população. O desenvolvimento, por sua vez, preocupa-se com a geração de riquezas sim, mas tem o objetivo de distribuí-las, de melhorar a qualidade de vida de toda a população, levando em consideração, portanto, a qualidade ambiental do planeta (MENDES, 2008).

Mas será que o homem está consciente de sua responsabilidade perante a sociedade, a vida em todas as suas formas e o planeta?

Torna-se necessário uma nova abordagem de exploração dos recursos naturais do planeta, que pode ser considerado como um grande organismo vivo, um superorganismo que tenta sempre se adaptar as perturbações produzidas pelo desenvolvimento humano (SEBILIA, 2007).

\section{CONSIDERAÇÕES FINAIS}

O conceito de DS embora criado há vários anos, ainda está em fase de desenvolvimento e sem prazo para conclusão, sua temática provoca discussões em todos os países, ao passo que o bem comum da humanidade depende muito do nosso presente, das nossas atitudes com as relações econômicas e naturais.

Contudo, nota se que o capitalismo está impregnado na consciência da maioria da população, o lucro é objeto alvo de qualquer investimento e as questões socioambientais são deixadas de lado.

Diante deste cenário, fica em evidencia a necessidade de construir novos hábitos para as futuras gerações, promover uma reeducação ética e moral.

$\mathrm{Na}$ qualidade de seres racionais, a raça humana tem o livre arbítrio, o poder de pensar e realizar ações, tal virtude nos dá o ônus de assumir inteiramente a responsabilidade 
não só pelas questões ambientais, mas também pela busca contínua do desenvolvimento sustentável e da melhora da qualidade de vida de todos os seres vivos de nosso planeta.

Para além do debate acerca do DS, cabe salientar o perigo de acreditar que ele funcionará como uma fórmula mágica para resolver os problemas socioambientais, seu maior mérito talvez resida no fato de que com ele abriu-se um espaço para o debate acerca de nossa responsabilidade para com nossos atos, e que estes atos por mais pessoais que sejam alcançam uma escala global e, portanto nossa ação tem que ser local, mas com uma visão global.

\section{Referências}

CANEPA, Carla. Cidades Sustentáveis: o município como lócus da sustentabilidade. São Paulo: Editora RCS, 2007.

CARVALHO, I. A Invenção ecológica. Porto Alegre: Editora da UFRGS, 2001.

CASTRO, Moacyr. A natureza é a alma do negócio. Revista Jurídica Consulex, Brasília, 317 pg 63 a 65, março de 2010.

FERREIRA, Leila da Costa. A questão ambiental: sustentabilidade e políticas públicas no Brasil. São Paulo: Boitempo Editorial, 1998.

GODARD, Olivier. A gestão integrada dos recursos naturais e do meio ambiente: conceitos, instituições e desafios de legitimação- In: Paulo Freire Vieira e Jacques Weber (Org.) tradução: Anne Sophie de Pontbriand Vieira, Christilla de Lassus.- Gestão de recursos naturais renováveis e desenvolvimento: novos desafios para a pesquisa ambiental. São Paulo: Cortez, 1997.

IACOMINNI, Vanessa. Biopirataria de Material Genético Humano uma discussão oportuna. Revista Jurídica Consulex , Brasília: p38, 40, fevereiro, 2011.

MENDES, Marina Ceccato. Desenvolvimento sustentável. Disponível em: <http://educar.sc.usp.br/biologia/textos/m_a_txt2.html>. Acesso em: 23 abr. 2014.

PRAHALAD, C. K. A Riqueza na base da pirâmide: como erradicar a pobreza com o lucro. Porto Alegre: Bookman, 2005.

PÁDUA, S.; TABANEZ, M. (orgs.). Educação ambiental: caminhos trilhados no Brasil. São Paulo: Ipê, 1998.

REIGOTA, M. Desafios à educação ambiental escolar. In: JACOBI, P. et al. (orgs.). Educação, meio ambiente e cidadania: reflexões e experiências. São Paulo: SMA, 1998. p.43-50.

RODRIGUES, Marcelo Abelha. Instituições de direito ambiental. Vol I - Parte Geral,

São Paulo: Max Limonad, 2002.

SEBILIA, Andres Salomon Cohen; Lixo: Uma Radiografia de nossa Sociedade. <http://www.sesc-se.com.br-educação-Monografia> 2007. Acesso em: 23 abr. 2014. 
TENÓRIO, Fernando Guilherme; NASCIMENTO, Fabiano Christian Pucci do,; Fundação Getulio Vargas. Responsabilidade social empresarial: teoria e prática. 2. ed. Rio de Janeiro (RJ): 2006 Ed. da FGV.

VEIGA, José Eli da. Cidades Imaginárias - o Brasil é menos urbano do que se calcula. Campinas: Editora da Unicamp, 2005. 